\title{
RECENT VALIDATION STUDY OF THE TECHNIQUE FOR EXPRESS EVALUATION OF BURNUP IN LEAKING FUEL ASSEMBLIES OF WWER POWER UNITS
}

\author{
O.V. Vilkhivskaya1, I.A. Evdokimov', V.V. Likhanskii², and E.Yu. Afanasieva1 \\ ${ }^{1}$ SRC RF TRINITI, 12 Pushkovykh Street, Moscow, Troitsk, 108840, Russia \\ ${ }^{2}$ NRC "Kurchatov Institute", 1 Akademika Kurchatova pl., Moscow, 123182, Russia
}

vilhivskaya_olga@mail.ru,i_a_evdokimov@rambler.ru, likhansk@mail.ru, afanasievah@inbox.ru

\begin{abstract}
The present work continues the series of papers on the revision of the conventional technique for evaluation of leaking fuel burnup during reactor operation at nuclear power plants (NPPs). The focus was made on reduction of uncertainties in evaluation of leaking fuel burnup in modern fuel cycles at WWER-1000 power units. A set of models was proposed for express calculation of the build-up of caesium isotopes in fuel and to relate ${ }^{134} \mathrm{Cs} /{ }^{137} \mathrm{Cs}$ activity ratio with fuel burnup for each rod in the core. These models are based on routine neutronic calculations of pin-by-pin linear heat generation rates which are performed at NPPs for each particular fuel cycle with particular core loading pattern (however, these calculations do not provide data on caesium inventory in fuel). Previously, the proposed models have been validated against several practical cases. This latest validation study relied on the analysis of the most recent fuel cycles at two NPPs that reported spike-events and identified the leaking fuel assemblies (LFAs) after the reactor shutdown. The calculated ${ }^{134} \mathrm{Cs} /{ }^{137} \mathrm{Cs}$ activity ratios in the fuel of the LFAs were compared to the NPPs data on the activity measurements, and to the post-irradiation examination (PIE) data provided for one FA. A reasonable agreement between the model predictions and the experimental data on ${ }^{134} \mathrm{Cs} /{ }^{137} \mathrm{Cs}$ activity ratios in the fuel as a function of its burnup is shown for the advanced FA designs in modern fuel cycles.
\end{abstract}

KEYWORDS: WWER-1000, leaking fuel burnup, spike-event, ${ }^{134} \mathrm{Cs} /{ }^{137} \mathrm{Cs}$ activity ratio.

\section{INTRODUCTION}

Radiation safety assurance procedures at operating WWER and PWR power units worldwide include monitoring of activity of the reference radionuclides in the primary coolant (PC). Accurate preliminary evaluation of a leaking fuel burnup during reactor operation is still a challenging issue at modern NPPs, [1]. Solving this issue would accelerate the LFA identification in the core during the maintenance outages at power units and facilitate the search for a proper substitute in spent fuel pools. Currently, reliable identification of leaking FAs of advanced designs requires taking into account operational features of modern fuel cycles [2] at WWER-1000 and WWER-1200 power units, with a perspective power uprating up to $107 \% \mathrm{~N}_{\text {nom }}$ (thermal power).

In case of fuel failures and release of radionuclides into the PC, one of the most sensitive indicators of the leaking fuel burnup for WWER and PWR power units is the ratio of ${ }^{134} \mathrm{Cs}$ and ${ }^{137} \mathrm{Cs}$ activity values measured in the PC during an activity spiking event recorded at interim power drops or at reactor shutdown, [2-5]. A 
common approach to evaluation of the leaking WWER FAs burnup at NPPs is to use a correlation of ${ }^{134} \mathrm{Cs} /{ }^{137} \mathrm{Cs}$ activity ratio as function of fuel burnup from the Guidance Document for NPPs discussed in [2]. This correlation is based on averaging of neutronic calculations for typical WWER fuel cycles applied in the early 2000-s; this technique was revised in an updated document [6], taking into account the differences in evolution of caesium (Cs) content in fuel pellets and in voids inside a fuel rod (see figure 6).

However, the analysis of spike events $[2,3,5]$ has recently shown some noticeable discrepancies with this technique [6] for elongated fuel cycles that imply higher fuel enrichment and presence of burnable neutron absorbers (U-Gd rods). These factors entail hardening of the neutron spectrum (see figure 1) that affects the effective neutron capture cross-section ${ }^{133} \mathrm{Cs}(\mathrm{n}, \gamma){ }^{134} \mathrm{Cs}$ in the resonance energy region $[4,8]$, while accumulation of ${ }^{137} \mathrm{Cs}$ and ${ }^{133} \mathrm{Cs}$ in fuel is practically linear with fuel burnup. This may result in considerably higher ratios of ${ }^{134} \mathrm{Cs}$ and ${ }^{137} \mathrm{Cs}$ concentrations in the fuel at the same burnup level.

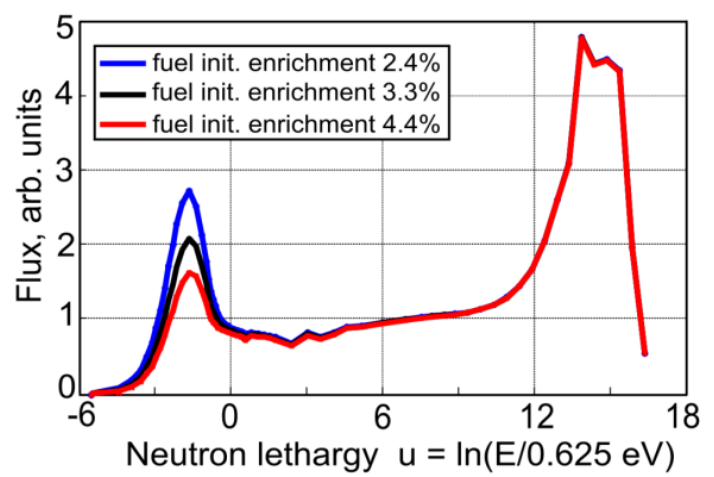

Figure 1. Example of calculated neutron flux spectra in a fuel pellet in WWER-1000 cells with the SVL code [7] (concentration of boric acid $2.8 \mathrm{~g} / \mathrm{kg}$, fuel temperature $1024 \mathrm{~K}$ )

Currently, it is mandatory to perform a standard pin-by-pin neutronic calculation for the evolution of linear heat generation rates (LHGRs) and fuel burnup before every fuel cycle at WWER power units. However, these calculations do not provide data on Cs inventory in the fuel pellets. Therefore, additional techniques should be utilised for taking into account features of Cs build-up rates in fuel of different rods/FAs in each particular fuel cycle. This technique has been elaborated in the series of papers [2-5]. These papers were focussed on the analysis of fuel operating conditions in modern fuel cycles at WWER-1000 power units and improvement of the existing burnup evaluation technique during reactor operation. The models for an express evaluation of the ${ }^{134} \mathrm{Cs} /{ }^{137} \mathrm{Cs}$ activity ratio versus fuel burnup were proposed to estimate the effect of the production rate of Cs isotopes in fuel depending on the FA's irradiation history and the neutron spectrum parameters in each particular fuel cycle. Detailed description of the model assumptions used for the fuel burnup and Cs inventory calculations for $\mathrm{UO}_{2}$ and $(\mathrm{U}, \mathrm{Gd}) \mathrm{O}_{2}$ rods are provided in open access conference proceedings $[4,5]$. Thus, in this paper, Section 2 only outlines the basic concepts of these models, and a closer attention is given to the models validation procedure in Sections 3 and 4.

\section{BASIC CONCEPTS OF THE MODELS}

Proposed simplified models provide an opportunity for fast and reliable evaluation of cesium inventory in fuel taking into account the irradiation history of each particular FA in the WWER core, [2, 4]. These models utilise the actual LHGR evolution of a Gd-doped fuel rod and the LHGRs of adjacent fuel rods in the FA (obtained by routine neutronic calculations at NPPs). A two-group approximation is adopted for the neutron flux distribution (one for thermal energy neutrons, and the other is for epithermal energy neutrons). A convention for the effective reaction cross-sections in thermal neutron reactors proposed by Westcott et al., [2], was used as well. The parameter $\gamma$ defines the ratio of epithermal-to-thermal energy neutron 
interactions with fissile nuclides (hardness of the neutron spectrum). A changing contribution of epithermal and thermal energy neutrons into the total LHGR of a FA during the cycle results in differences of ${ }^{134} \mathrm{Cs} /{ }^{137} \mathrm{Cs}$ activity ratio in fuel of $\mathrm{UO}_{2}$ and $(\mathrm{U}, \mathrm{Gd}) \mathrm{O}_{2}$ rods in the same $\mathrm{FA}$, [4].

The calculations for Cs production in the fuel accounts for the initial hardness of the neutron spectrum $\left(\gamma_{0}\right)$ at the beginning of an FA's operation and during its evolution in each core cycle $-\gamma(t)$. The models assume that the total LHGR of a rod ( $L P^{f r}$ - of an $\mathrm{UO}_{2}$-fuel rod, $L P^{g r}$ - of a Gd-doped fuel rod) with fuel enrichment in ${ }^{235} \mathrm{U}\left(e n r_{f r}\right.$ and $\left.e n r_{g r}\right)$ is comprised of the following contributions, see relation (1a): the interaction of fast neutrons with ${ }^{238} \mathrm{U}$, and interaction of the epithermal $\left(L P_{E T}\right)$ and thermal $\left(L P_{T}\right)$ neutrons with ${ }^{235} \mathrm{U}$ in the fuel, $[4,5]$. Fast neutron fission rate for ${ }^{238} \mathrm{U}$ is assumed proportional to the total fission rate in the FA, the contribution of ${ }^{238} \mathrm{U}$ fissions into the total LHGR of a rod and is calculated by the relation (1b).

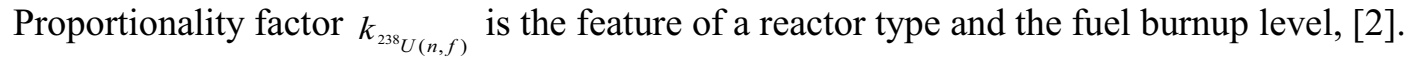

The models take into account layered burn-out of gadolinium isotopes in a "fresh" Gd-doped fuel rod, which results in increasing of its total LHGR during the first fuel cycle, predominantly attributable to ${ }^{235} \mathrm{U}$ fissions in the thermal energy region, [4]. The relative initial contribution to the total LHGR of a Gd-doped $\operatorname{rod}\left(L P_{T, g r}^{t=0}\right)$ from interactions of thermal neutrons with ${ }^{235} \mathrm{U}$ is calculated using the relation $(1 \mathrm{c})$, where parameter $k_{T}^{g r}$ is a function of the initial enrichment in $\mathrm{Gd}_{2} \mathrm{O}_{3},[3,4]$ :

$$
\begin{aligned}
& L P(t)=L P_{238}(n, f) \\
& L P_{238_{U}(n, f)}(t)=k_{238}(t)+L P_{E T}(t)+L P_{T}(t), \\
& L P_{T, g r}^{t=0}=k_{T}^{g r}\left(L P_{g r}^{t=0}-k_{238} \cdot(t)\right. \\
& . L(n, f)
\end{aligned}
$$

At the beginning of the fuel cycle, ${ }^{10} \mathrm{~B}$ and ${ }^{155,157} \mathrm{Gd}$ isotopes (in Gd-doped rods of the feed FAs) contribute significantly to the capture of thermal neutrons, so the contribution of thermal neutron flux into the total power of a FA changes with time. Resonance neutron absorption by ${ }^{235} \mathrm{U}$ is less affected, thus the flux of the resonance neutrons $\Phi_{E T}(t)$ changes weakly with time, taking into account possible minor changes in LHGRs from a sustained constant value (described by the relation 3). Using this assumption, the initial hardness of the neutron spectrum $\gamma_{0}$ and its evolution during the core cycle $\gamma(t)$ can be calculated from the relation:

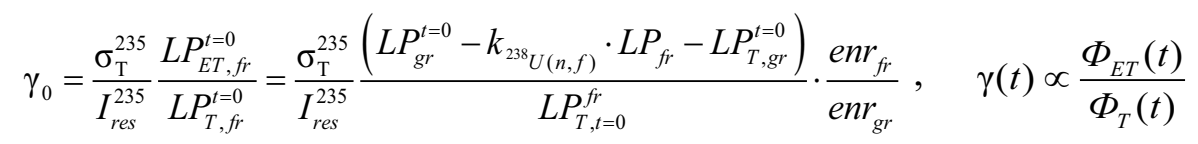

where $\sigma_{\mathrm{T}}^{235}$ is the thermal fission cross-section of ${ }^{235} \mathrm{U}, I_{\text {res }}^{235}$ is the resonance integral for ${ }^{235} \mathrm{U}$ fissions, $\Phi_{T}(t)$ and $\Phi_{E T}(t)$ are the thermal/epithermal neutron flux values, respectively, $\left[\mathrm{m}^{-2} \mathrm{~s}^{-1}\right]$. Assuming that the relation between FA's LHGR and epithermal neutron flux $\Phi_{E T}(t)$ varies weakly during the cycle, and taking into account the calculated initial $(t=0)$ thermal neutron flux $\Phi_{T_{0}}$ and $\gamma_{0}$, the values of $\gamma(t), \Phi_{T}(t)$ and $\Phi_{E T}(t)$ are estimated at each time step $(j)$ over the cycle time using the fixed-point iteration method:

$$
\frac{\gamma_{0} \Phi_{T_{0}}}{L P_{f r}^{t=0}}=\frac{\gamma_{j} \Phi_{T_{j}}}{L P_{f r}^{j}}
$$

Therefore, the following set of equations is incorporated into the models [2] to describe the rate of buildup of caesium isotopes $\left({ }^{133,134,137} \mathrm{Cs}\right)$ in the fuel: 


$$
\begin{aligned}
& \dot{n}_{133}(t)=y_{133}^{\text {eff }}(t) \dot{F}(t)-\sigma_{133}(t) \Phi_{T}(t) n_{133}(t) \\
& \dot{n}_{134}(t)=\sigma_{133}(t) \Phi_{T}(t) n_{133}(t)-\sigma_{134}(t) \Phi_{T}(t) n_{134}(t)-\lambda_{134} n_{134}(t), \\
& \dot{n}_{137}(t)=y_{137}^{\text {eff }}(t) \dot{F}(t)-\lambda_{137} n_{137}(t)
\end{aligned}
$$

where $n_{133,134,137}(t)$ is the atomic density of a Cs nuclide $\left[\mathrm{m}^{-3}\right], \lambda_{133,134,137}$ - radioactive decay constant of the nuclide $\left[\mathrm{s}^{-1}\right], \sigma_{133,134,137}(t)$ is the full neutron absorption cross-section of the nuclide $\left[10^{-28} \mathrm{~m}\right]$ of the corresponding Cs nuclides: $\sigma_{i}(t)=\sigma_{i}^{\mathrm{T}}+I_{i}^{r e s} \cdot \gamma(t), \mathrm{i}=133,134,137, \Phi_{T}(t)$ is the averaged thermal neutron flux $\left[\mathrm{m}^{-2} \mathrm{~s}^{-1}\right]$ calculated by the relation (3), $\dot{F}(t)$ - the total fission rate [3] of the primary fissile nuclides $\left({ }^{235} \mathrm{U},{ }^{239,241} \mathrm{Pu}\right)$ in the fuel volume $\left[\mathrm{m}^{-3} \mathrm{~s}^{-1}\right]$. The effective fission yield $y_{i}^{\text {eff }}(t)$ for ${ }^{133,134,137} \mathrm{Cs}$ isotopes $(i=133,134,137)$ per fission of heavy atoms is described by the following relation with respect to the evolution of their concentrations:

$$
y_{i}^{\text {eff }}(t)=\frac{y_{i}^{235} n_{235}(t) \sigma_{f}^{235}+y_{i}^{239} n_{239}(t) \sigma_{f}^{239}+y_{i}^{241} n_{239}(t) \sigma_{f}^{241}}{n_{235}(t) \sigma_{f}^{235}+n_{239}(t) \sigma_{f}^{239}+n_{241}(t) \sigma_{f}^{241}}
$$

Therefore, the presented models enable changes to calculate the ${ }^{134} \mathrm{Cs} /{ }^{137} \mathrm{Cs}$ activity ratio in $\mathrm{UO}_{2}$-fuel taking into account the features of FAs operation in every particular fuel cycle with its specific core loading pattern. Calculations with these models utilize JEFF-3.3 nuclear data library that takes into account the overlapping of ${ }^{238} \mathrm{U}$ and ${ }^{133} \mathrm{Cs}$ first resonances: $\mathrm{E}_{\mathrm{r}}^{\mathrm{U}-238}=6.67 \mathrm{eV} / \mathrm{E}_{\mathrm{r}}^{\mathrm{Cs}-133}=5.59 \mathrm{eV}[4,5]$.

As an example, Figure 2 provides the comparison of the model calculation results for an $\mathrm{UO}_{2}$ and Gd-doped fuel rod in a leaking TVS-2M after the 18-month fuel cycle, see [4]. Model calculations utilised the average LHGR of an $\mathrm{UO}_{2}$-fuel rod $\left(4.4 \%\right.$ in $\left.{ }^{235} \mathrm{U}\right)$ with the maximal average burnup, and of a Gd-doped fuel rod $\left(3.6 \%\right.$ in ${ }^{235} \mathrm{U}$ ) that was found to be leaking during PIE. Calculation results for the ${ }^{134} \mathrm{Cs} /{ }^{137} \mathrm{Cs}$ activity ratios in fuel are shown along with the PIE results of gamma-scanning of fuel columns in these rods taking into account the time period elapsed between the FA's discharge from the reactor core $\left(\mathrm{T}_{\mathrm{EOC}}\right)$ and examination in hot cells $\left(\mathrm{T}_{\mathrm{PIE}}\right)$. The recorded Cs activity ratio in the PC during the spike-event at the reactor shutdown is shown by the red dashed-line interval. This example highlights the importance of the differences in the Cs build-up rates in $\mathrm{UO}_{2}$ and Gd-doped rods in analysis of activity spike-events at the NPPs: a lower value of $(\mathrm{U}, \mathrm{Gd}) \mathrm{O}_{2}$ fuel burnup may correspond to a comparatively high value of ${ }^{134} \mathrm{Cs} /{ }^{137} \mathrm{Cs}$ activity ratio, particularly in the first cycle of the FA's operation.
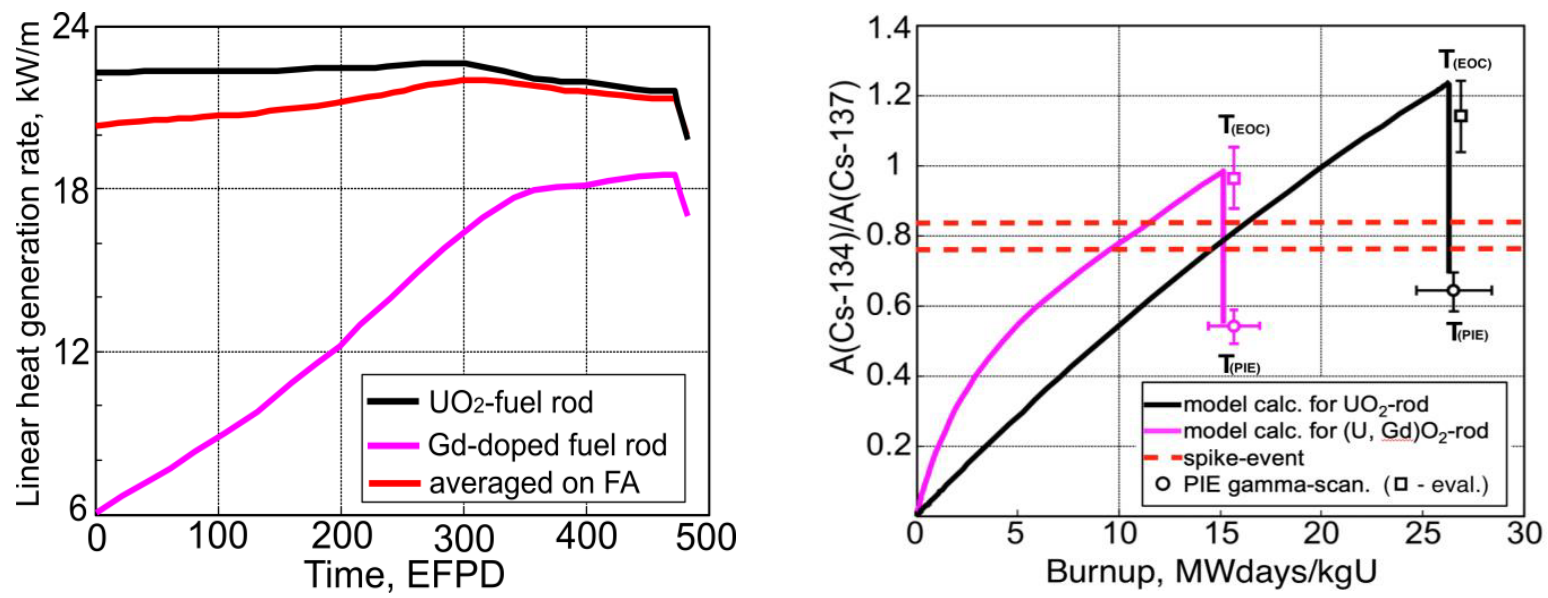

Figure 2. Example of the model calculation results with the PIE results for gamma-scanning of the fuel rods in TVS-2M analysed in the previous work [4] 


\section{VALIDATION METHOD}

Validation of the models for fast evaluation of fuel burnup in leaking FAs relies on the data provided by four NPPs with WWER-1000 power units (type V-320, [2]). The data includes the reactor core power history, parameters of the coolant clean-up system, activities of the reference radionuclides in the PC, and average LHGRs of the FAs obtained with neutronic calculations at the NPPs. At the end of each considered fuel cycle (the time period of 2014-2018), sipping leakage tests in the mast of the refuelling machine were performed for all the FAs in the core. Leaking fuel testing in the casks of the failed fuel detection system (FFDS) was performed for the suspect FAs in the core, and the activities of the reference radionuclides in the water samples from the cask circuit were measured. This procedure is described in papers $[9,10]$ in more detail. Thus, the leaking assemblies were identified, and their fuel burnup was reliably determined (see Table 1). Results of the suspect FAs' testing in the FFDS casks after the reactor shutdown (hereinafter, FFDS results) confirmed that all the leaking FAs considered in this paper were the only ones in the core in each corresponding fuel cycle.

Table I: Parameters of the failed FAs that were used for model calculations in the analysed cases

\begin{tabular}{|c|c|c|c|c|c|c|c|}
\hline \# & $\begin{array}{l}\text { Failed FA } \\
\text { type }\end{array}$ & $\begin{array}{l}\text { Pellet } \\
\text { design }\end{array}$ & $\begin{array}{l}\text { FA average } \\
\text { fuel } \\
\text { enrichment } \\
\text { in }{ }^{235} \mathrm{U} \text {, wt.\% }\end{array}$ & $\begin{array}{l}\text { Number } \\
\text { of } \mathrm{UO}_{2} / \\
(\mathrm{U}, \mathrm{Gd}) \mathrm{O}_{2} \\
\text { fuel rods }\end{array}$ & $\begin{array}{l}\text { Irradiation } \\
\text { period, } \\
\text { fuel } \\
\text { cycles } \\
\end{array}$ & $\begin{array}{l}\text { Available } \\
\text { PIE } \\
\text { results }\end{array}$ & $\begin{array}{l}\text { Calculated average } \\
\text { fuel burnup: } \\
\text { FA / leaky rod, } \\
\text { MWd/kgU }\end{array}$ \\
\hline 1 & TVSA-12 & \multirow{2}{*}{ solid } & 3.97 & $300 / 12$ & 1 & \multirow{2}{*}{$\begin{array}{c}\text { visual } \\
\text { inspection }\end{array}$} & $15.70 / 14.96$ \\
\hline 2 & TVSA-12 & & 4.60 & $300 / 12$ & 2 & & $30.54 / 31.65$ \\
\hline 3 & TVS-2M & annular & 4.20 & $294 / 18$ & 2 & hot cell & $40.96 / 41.0$ \\
\hline
\end{tabular}

An exceptional opportunity for the model validation exercise in this study is represented by the activity spike-events observed in cases \#2 and \#3. Cases \#1 and \#2 denote two subsequent fuel cycles at the same power unit, where the location of the damaged/suspect fuel rod was revealed during visual inspection of the failed FAs after the reactor shutdown. In case \#3, the leaking FA was examined in SSC RIAR hot cells after a cooling period at the NPP, the results of gamma-scanning of the damaged rod for an axial distribution of caesium radionuclides in fuel were provided. The previous paper [4] describes the details of the gammascanning procedure and the results of the collaboration with SSC RIAR for the data analysis and elaboration.

\section{VALIDATION OF THE MODEL CALCULATION RESULTS FOR ${ }^{134} \mathrm{CS} /{ }^{137} \mathrm{CS}$ ACTIVITY RATIO IN FUEL OF LEAKY FUEL ASSEMBLIES}

Isotopic inventory calculations with the previously developed code $[2,4,5]$ in this work are limited to the fast simulation of the build-up of Cs isotopes and estimation of the ${ }^{134} \mathrm{Cs} /{ }^{137} \mathrm{Cs}$ activity ratio in fuel that is used in the conventional technique [6] for the evaluation of fuel burnup at NPPs. Calculation results are compared to the recorded ${ }^{134} \mathrm{Cs} /{ }^{137} \mathrm{Cs}$ activity ratio at spike-events and to the FFDS testing results for each FA (correlated to the to the NPP data on the calculated fuel burnup in a suspect/identified leaking rod).

The data on the reactor operation parameters (provided by the NPPs) were processed using the Expert System (ES) [2, 5, 11]. Values of the specific activities of iodine radionuclides, noble gases, and Cs in the PC were measured with an uncertainty allowance of $\sim 10.0 \%$ at the power units. The NPPs data for cases $\# 1, \# 2$, and \#3 are shown in figures 3 and 5: the upper graph shows the time evolution of the reactor thermal power along with the flow rate to ion-exchange filters $\left(\mathrm{Q}_{\mathrm{IEF}}\right)$ to highlight the moment when the activity spike-event occurs; the bottom graph shows the specific activities of ${ }^{134} \mathrm{Cs}$ and ${ }^{137} \mathrm{Cs}$ in the $\mathrm{PC}$ for the 
evaluation of the activity spiking amplitude. When a spike-event occurs, activities of Cs isotopes are evaluated subtracting the background activity level (highlighted in orange), and then the values of ${ }^{134} \mathrm{Cs} /{ }^{137} \mathrm{Cs}$ spiking activity ratios are processed in time during (typically, for $1-2$ days, highlighted in red). Therefore, ${ }^{134} \mathrm{Cs} /{ }^{137} \mathrm{Cs}$ activity ratio "intervals" in figures that provide the comparison between the model calculation results and the NPPs' data represent the minimum and maximum values of the recorded spiking activity ratio.

\subsection{Operational Parameters of TVSA-12 \#1 and \#2 and Model Calculation Results}

For the analysed cases \#1 and \#2 that correspond to subsequent fuel cycles at the same power unit, spiking of Cs activities in the PC was recorded after the reactor shutdown. The NPP data for these cycles are presented in Figure 3. The recorded spiking ${ }^{134} \mathrm{Cs} /{ }^{137} \mathrm{Cs}$ activity ratio values in the PC were $0.76 \div 0.79$ in case \#1 (see figure 3, left), and 1.5 $\div 1.63$ in case \#2 (see figure 3, right). Following the sipping leakage tests after each fuel cycle, the suspect leaking TVSA-12 \#1 and \#2 were additionally tested in the FFDS cask (see Table 1 for the details).

In both cases $\# 1$ and $\# 2$, the location of the damaged/suspect $\mathrm{UO}_{2}$-fuel rod was identified during visual inspection, therefore the calculations for the actual LHGR of these rods were additionally performed at the NPP (shown in figures 4 and 5, respectively). Visual inspection of TVSA-12 \#2 revealed evidence of cladding degradation for a rod in the peripheral row (swollen cladding in the lower part of the rod), typical for a local severe hydriding damage that may lead to cladding fracture. However, these fractures cannot be always detected during visual inspections at the NPPs due to the limitation of the cladding surfaces available for observation.
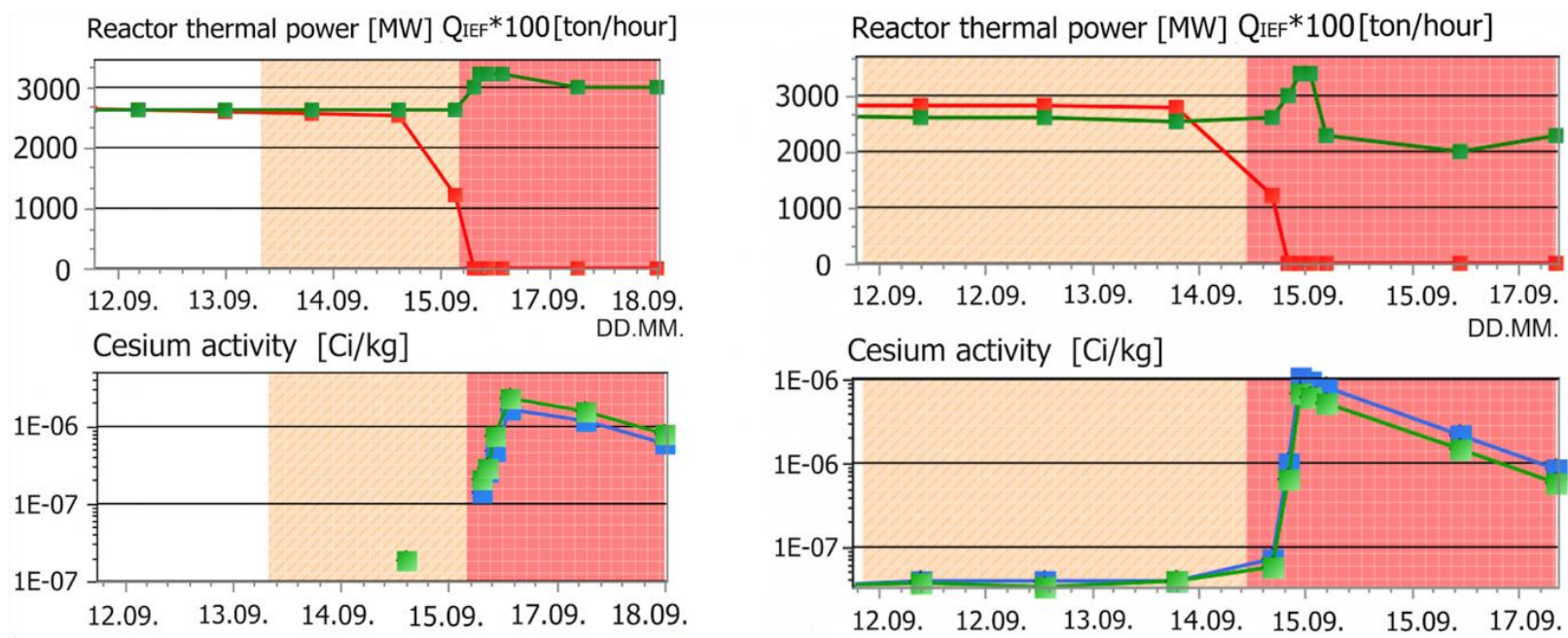

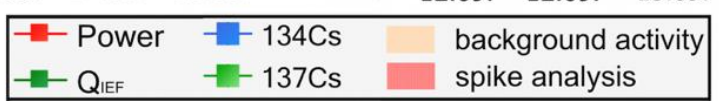

Figure 3. NPP data for caesium activity spike-event after the reactor shutdown: case \#1 (left) and \#2 (right)

Figure 4 shows the comparison of the measured ${ }^{134} \mathrm{Cs} /{ }^{137} \mathrm{Cs}$ activity ratio at the spike-event and in the water sample from the FFDS cask circuit for TVSA-12 \#1. The model calculation results of Cs activity ratio for the damaged rod in TVSA-12 \#1 overestimate the results of the FFDS testing but agree with the NPP data on the activity spike-event. This discrepancy could be attributed to the differences in the activity release dynamics during reactor operation and in the course of the FFDS testing procedure in a cask. 

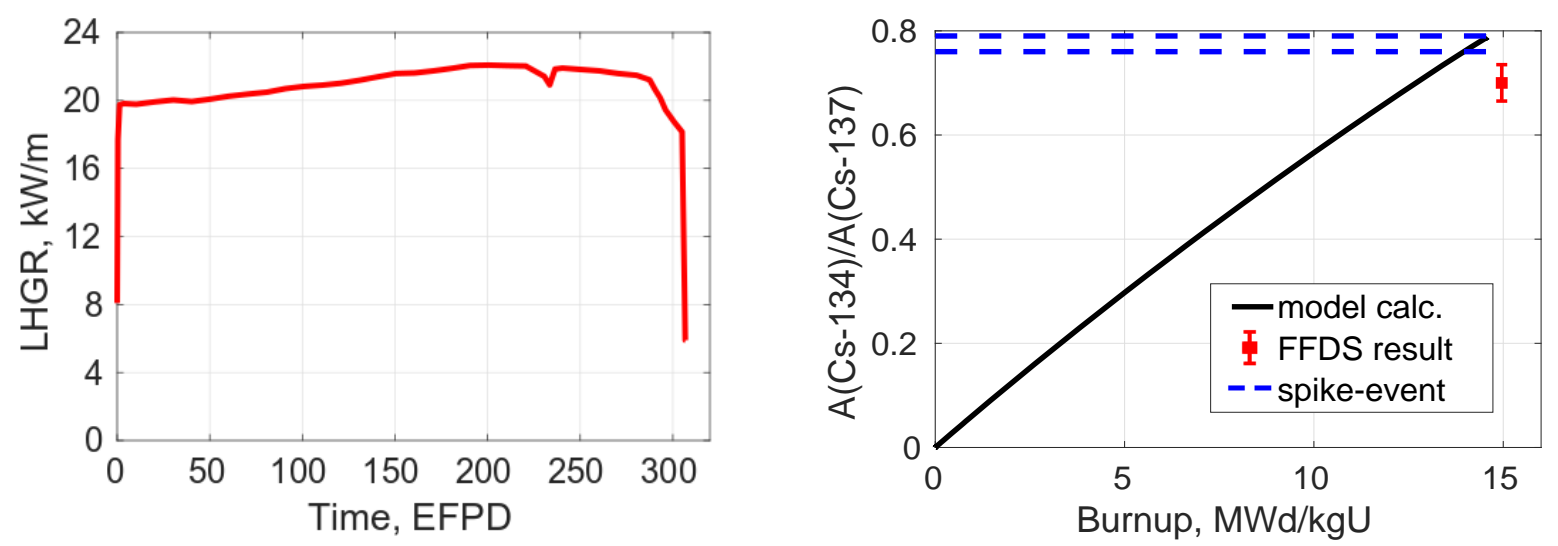

Figure 4. TVSA-12 \#1, suspect rod: average LHGR and comparison of ${ }^{134} \mathrm{Cs} /{ }^{137} \mathrm{Cs}$ activity ratio

Detailed analyses of the activity in the PC during reactor operation and evaluations of the activity release from a leaking fuel rod for the case \#1 are discussed in more detail in [12]. These evaluations were performed using the RTOP-CA fuel performance code $[3,10,12]$, which is capable of running simulations of time-dependent fission product release both during steady-state reactor operation and at activity spikeevents during power transients. Validation studies for the RTOP-CA models have been performed against the results of the in-pile reactor experiments and the activity measurement results at NPPs.

Figure 5 shows the comparison of the measured ${ }^{134} \mathrm{Cs} /{ }^{137} \mathrm{Cs}$ activity ratio at the spike event and in the water sample from the FFDS cask circuit for TVSA-12 \#2. It can be seen that the model calculation results of Cs activity ratio for the leaking rod in TVSA-12 \#2 slightly underestimate provided NPP data.
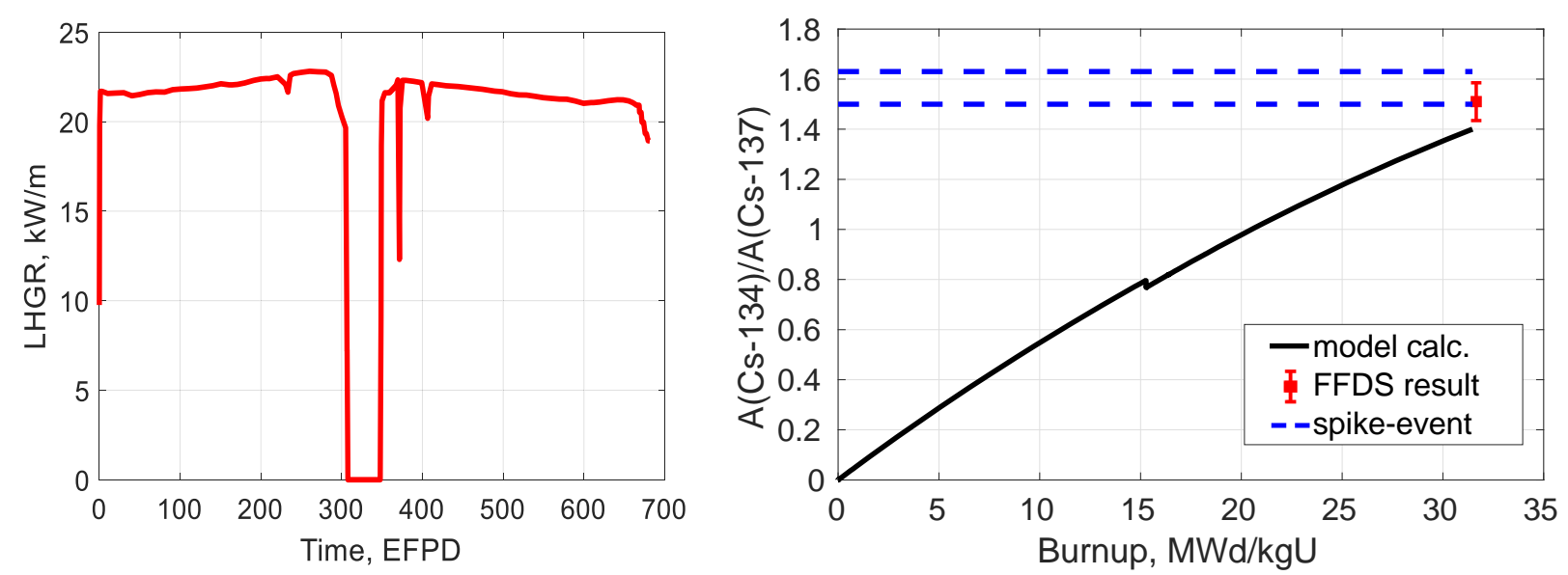

Figure 5. TVSA-12 \#2, suspect rod: average LHGR and comparison of ${ }^{134} \mathrm{Cs} /{ }^{137} \mathrm{Cs}$ activity ratio

Figure 6 shows the example of applying the correlations ${ }^{134} \mathrm{Cs} /{ }^{137} \mathrm{Cs}$ activity ratios from [6] for evaluation of leaking fuel burnup utilizing ${ }^{134} \mathrm{Cs} /{ }^{137} \mathrm{Cs}$ activity ratio at the end of cycle (EOC) for both spike-events. The regulatory guidelines [6] provide the correlations for the ${ }^{134} \mathrm{Cs} /{ }^{137} \mathrm{Cs}$ activity ratios in "voids inside a fuel rod" and "in fuel pellets" that yield the bottom and the upper estimates for the fuel burnup, respectively. Thus, applying the correlation "content of caesium in voids inside a fuel rod" to the spike-event data for the case \#2 yields that the minimal burnup of the leaking TVSA-12 \#2 should be $36 \mathrm{MWd} / \mathrm{kgU}$. This shows 
a discrepancy between the estimated fuel burnup applying the criterion [6] and the results of the FFDS testing in the case \#2 (see Table 1): TVSA-12 \#2 average fuel burnup was estimated to be $30.54 \mathrm{MWd} / \mathrm{kgU}$ at the moment of discharge (and $31.65 \mathrm{MWd} / \mathrm{kgU}$ in the failed fuel rod).

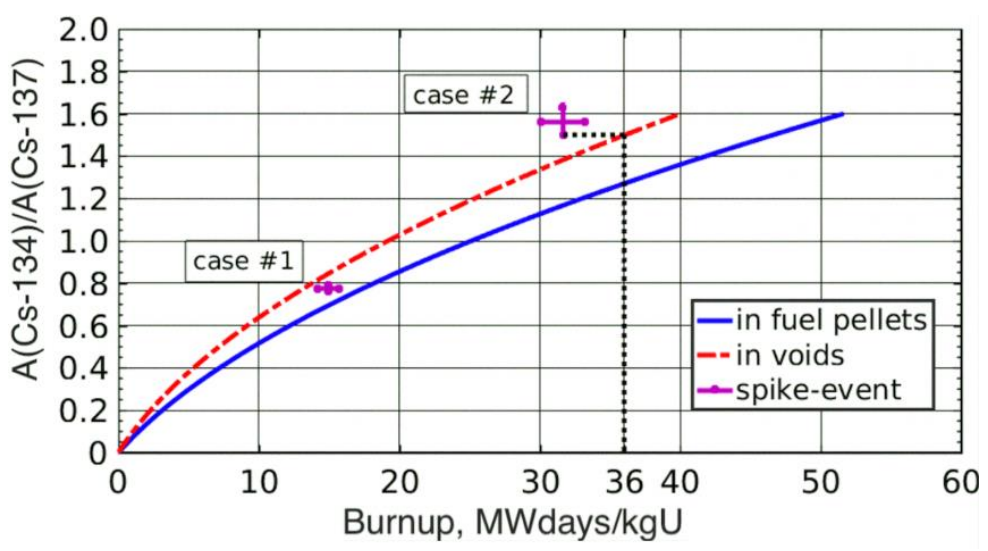

Figure 6. The results of applying the criterion [6] for evaluation of leaking fuel burnup utilizing ${ }^{134} \mathrm{Cs} /{ }^{137} \mathrm{Cs}$ activity ratio at the spike-events in cases \#1 and \#2

One of possible explanations for the discrepancy between the predicted fuel burnup values utilising the technique [6] and the FFDS testing results in case of fuel with solid pellets could be attributed to washout of Cs predominantly from the pellet periphery during the spike-event. Due to the resonance spatial selfshielding effect in uranium, the observed non-uniform fuel burnup radial profile suggests that burnup at the pellet periphery may considerably exceed the average pellet burnup. Possible mechanism of the processes that were involved in the observed Cs radionuclides release and radionuclides washout from the fuel pellet periphery is described in [11] in more detail. The standard technique [6] for evaluation of leaking fuel burnup utilizing the Cs activity at spike-events does not take into account the features of mass-transfer in a leaking fuel rod with solid fuel pellets (at least, at burnup levels that imply an onset of pellet-cladding interaction). Case \#2 has shown that this may result in the incorrect evaluation of a leaking FA operation period by spike-event analysis, suggesting that the improvement of the technique should also take into account the features of mass-transfer of the radionuclides in cases of leaking fuel with solid pellets.

\subsection{Operational Parameters of TVS-2M \#3 and Model Calculation Results}

In the analysed case \#3 spiking of Cs activities in the PC was recorded at an interim reactor power drop and after the reactor shutdown, the NPP data are presented in Figure 7. Recorded ${ }^{134} \mathrm{Cs} /{ }^{137} \mathrm{Cs}$ activity ratio in the PC was in the rage of $1.62 \div 1.93$ for the interim spike-event (1), and $1.26 \div 1.98$ for the spike-event (2) after the reactor shutdown (see Figure 8). Preliminary analysis of the behaviour of released iodine and noble gas activity in $[12,13]$ suggested that the defect in a failed fuel rod was classified as gas leakage.

Examination of TVS-2M \#3 (with fuel blankets at the top and bottom of the fuel stack) in hot cells of SSC RIAR identified the $\mathrm{UO}_{2}$-fuel rod with a debris-induced damage under the bottom (first) spacer grid by visual inspection and eddy-current testing, [13]. Small size of this primary defect (less than 30 microns) was associated with the observed residual fragment of the debris that partially covered the void surface in cladding, thus reducing its effective diameter. Therefore, the Cs activity release from fuel was reported to be relatively low: within the uncertainty of its quantification by gamma-scanning in the fuel stacks of the leaking fuel rod and the adjacent rod, [13]. 


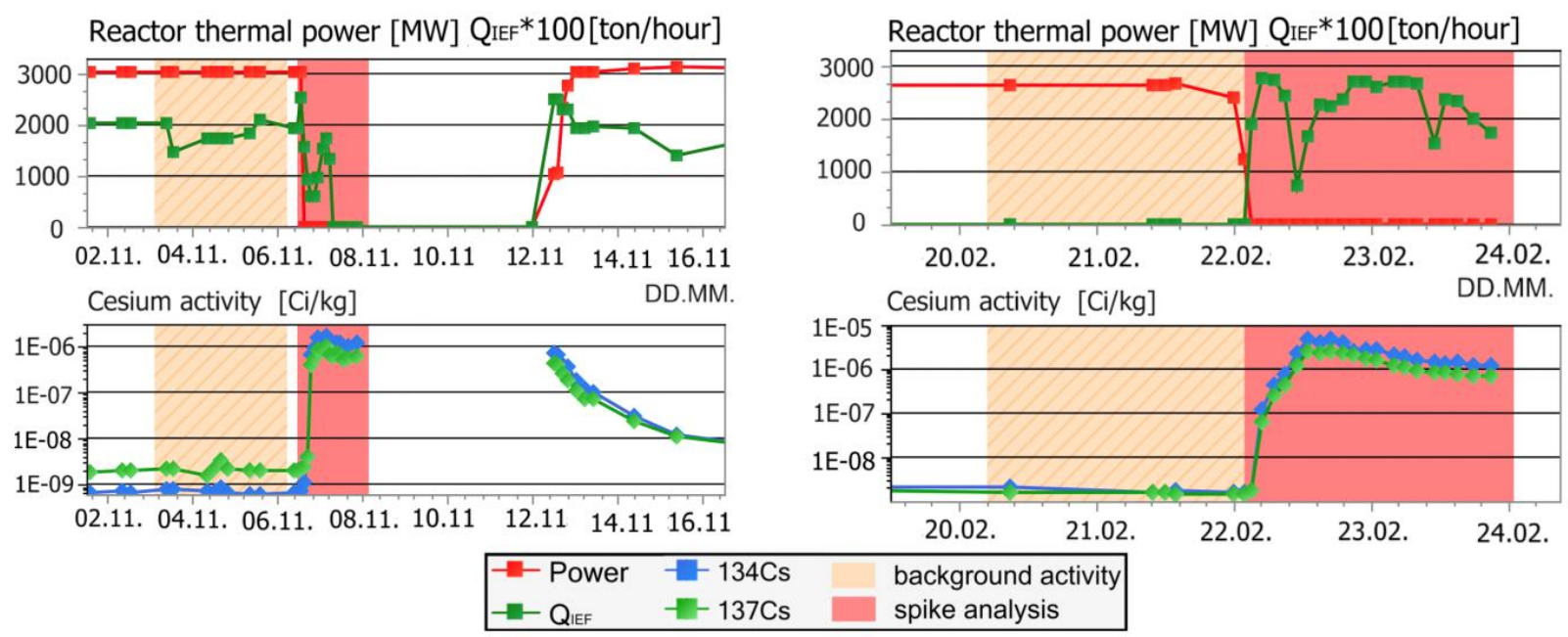

Figure 7. NPP data for caesium activity spike-event in case \#3: at interim power drop (left), and after the reactor shutdown (right)

The average LHGR of the leaking fuel rod in TVS-2M \#3 was gradually increasing from 13 to $20 \mathrm{~kW} / \mathrm{m}$

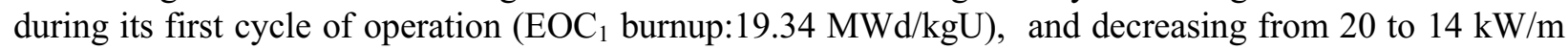
during the second cycle. Model calculation results for the ${ }^{134} \mathrm{Cs} /{ }^{137} \mathrm{Cs}$ activity ratio in fuel of TVS-2M \#3 along with the NPP's data and gamma-scanning results are shown in Figure 8. It can be seen that the model calculations of Cs activity ratio for TVS-2M \#3 are in good agreement with the experimental data. The evaluated results for the ${ }^{134} \mathrm{Cs} /{ }^{137} \mathrm{Cs}$ activity ratio obtained during gamma-scanning of the leaking fuel rod (gamma-scan) agree with the FFDS testing results for this FA (FFDS result) taking into account the uncertainties of these interrogation methods (shown in Figure 8).
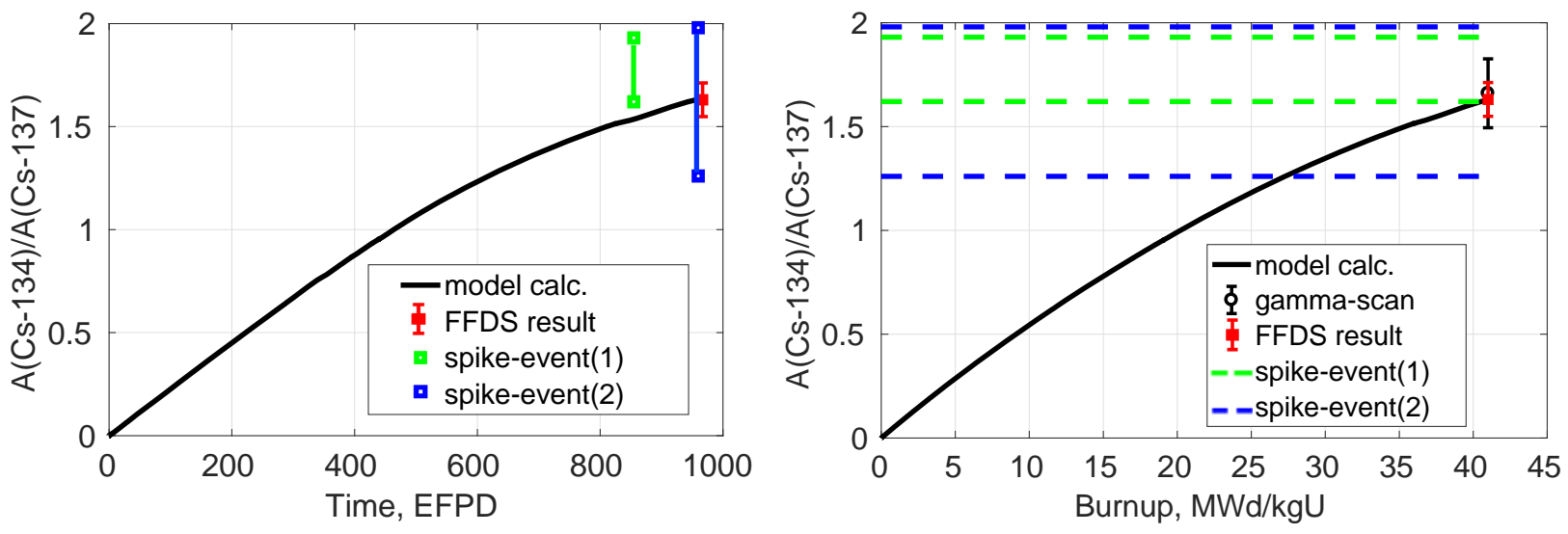

Figure 8. TVS-2M \#3, leaking rod: comparison of ${ }^{134} \mathrm{Cs} /{ }^{137} \mathrm{Cs}$ activity ratio in fuel as function of the FA operation time (left) and burnup (right) with the results of FFDS testing and gamma-scanning

\section{CONCLUSIONS}

A set of models has been elaborated for fast calculation of caesium inventory in $\mathrm{UO}_{2}$ and $(\mathrm{U}, \mathrm{Gd}) \mathrm{O}_{2}$ fuel rods for particular core loading pattern at NPPs. The input data for these models is based on the routine 
neutronic calculations performed at NPPs to characterise evolution of linear heat generation rate and burnup in fuel rods during the particular fuel cycle with a particular core loading pattern. However, these routine neutronic calculations do not provide data on caesium build-up in fuel.

The model predictions were compared to the coolant activity data at NPPs and results of hot cell examinations of leaking fuel in SSC RIAR. It is shown that there is a reasonable agreement between the calculations and the experimental data on ${ }^{134} \mathrm{Cs} /{ }^{137} \mathrm{Cs}$ activity ratios as a function of fuel burnup in $\mathrm{FAs}$ of advanced designs operated in modern fuel cycles. The proposed technique for caesium inventory calculations provides quick and reliable evaluation of leaking fuel burnup in the frame of analysis of primary coolant activity during operation of WWER-1000 power units.

Further improvement and validation of this technique is planned for the WWER fuel design with solid fuel pellets. The current study suggests that the model predictions for fuel with solid pellets could be more accurate if non-uniform burnup across the fuel pellets was properly taken into consideration. Moreover, additional studies will be performed on the mass-transfer in leaking fuel rods with solid fuel pellets with the RTOP-CA code. Some specific features of mass-transfer inside leaking fuel rods with solid pellets will be studied for situations when pellet-cladding interaction becomes the primary factor affecting the accuracy of the predictions of fuel burnup.

\section{REFERENCES}

1. Z. Hózer et al. "Leaking fuel impacts and practices." Report OECD-NEA No. NEA/CSNI/R(2014)10.

2. V.V. Likhanskii, O.V. Vilkhivskaya, S.A. Tokarev, "Modeling of burnup express-estimation for UO2fuel." J. Nucl. Eng. Des. 313, pp. 141-147 (2017).

3. Likhanskii V.V. et al. "Modified versions of the fuel performance codes RTOP and RTOP-CA." Proceedings of "TOPFUEL 2016", Boise, USA, pp. 963-972 (2016).

4. V.V. Likhanskii, O.V. Vilkhivskaya et al. "Engineering model for ${ }^{134} \mathrm{Cs}$ and ${ }^{137} \mathrm{Cs}$ production in $\mathrm{Gd}-$ doped fuel rods." Proceedings of "WRFPM 2017”, Jeju Island, Korea (2017).

5. O.V. Vilkhivskaya et al. "Extended validation of engineering models for express-method of burnup evaluation of WWER-1000 fuel elements." Proceedings of "TOPFUEL 2018", Czech Republic (2018).

6. RD EO 1.1.2.10.0521-2009. Standard Procedure for Monitoring the Cladding Integrity of Fuel Elements. FAs of the VVER-1000 Reactors, Rev. 2. Rosenergoatom, Moscow, Russia (2016).

7. Laletin N.I. et al. "Codes complex for quick transport 3D neutron calculations of WWER." Proceedings of the 1 $7^{\text {th }}$ Symposium of Atomic Energy Research, vol.1, Hungary, pp. 323-337 (2007).

8. S. Nakamura et al. "Measurement of Thermal Neutron Capture Cross Section and Resonance Integral of the Reaction ${ }^{133} \mathrm{Cs}(\mathrm{n}, \gamma){ }^{134 \mathrm{~m}, 134 \mathrm{~g}} \mathrm{Cs} . "$ J. Nucl. Sci. Technol. 36 (10), pp. 847-854 (1999).

9. V. G. Zborovskii et al. "Modeling of radionuclides release during cask leakage tests of failed fuel rods." Matem. Mod. 23 (7), pp.145-160 (2011, in Russian).

10.V.P. Povarov et al. "Developing and applying modern methods of leakage monitoring and state estimation of fuel at the Novovoronezh nuclear power plant." Therm.Eng. 61 (2), pp.123-132 (2014).

11.I.A. Evdokimov et al. "Development of Expert System for fuel monitoring and analysis in WWER-1000 units." Proceedings of the $9^{\text {th }}$ Int. Conf. on WWER Fuel Performance, Modeling and Exper. Support, Bulgaria (2011).

12.Borisov A.V. et.al. "Validation of the enhanced version of the RTOP-CA code designed for modeling the fission products release from failed fuel rod to the primary circuit of WWER." Proceedings of the $13^{\text {th }}$ Int. Conf. on WWER Fuel Performance, Modeling and Exper. Support, Bulgaria (2019).

13.A.V. Strozhuk et al. "Review of the causes of fuel failure in TVS-2M." SSC RIAR Annual Research Report for 2017, Dimitrovgrad, pp. 63-65 (2018, in Russian). 